ИЗВЕСТИЯ АКАДЕМИИ НАУК ЭСТОНСКОИ ССР. ТОМ 21 ХИМИЯ * ГЕОЛОГИЯ, 1972, N. 4

\title{
СОСТАВ И КОЛИЧЕСТВО ДЕТРИТА В ОТЛОЖЕНИЯХ СЕВЕРНОЙ ФАЦИАЛЬНОЙ ЗОНЫ ОРДОВИКА ПРИБАЛТИКИ
}

\author{
(ПО СКВАЖИНЕ РАПЛА)
}

Настоящая статья является продолжением исследований автором литологических особенностей двух (северной и осевой) структурно-фациальных зон ордовика Прибалтики. Первая статья (Пылма, 1972) была посвящена характеристике детрита в отложениях осевой фациальной зоны. Фактической основой при этом служил керн скв. Энгуре (Латвийская ССР), В данной статье изложены результаты изучения разреза скв. Рапла (Әстонская ССР) в северной фациальной зоне. В последующих публикациях будет проведено сравнение вещественного состава, структур и текстур двух названных выше фациальных зон Прибалтики, а также рассмотрены некоторые общие вопросы карбои: тного осадконакопления.

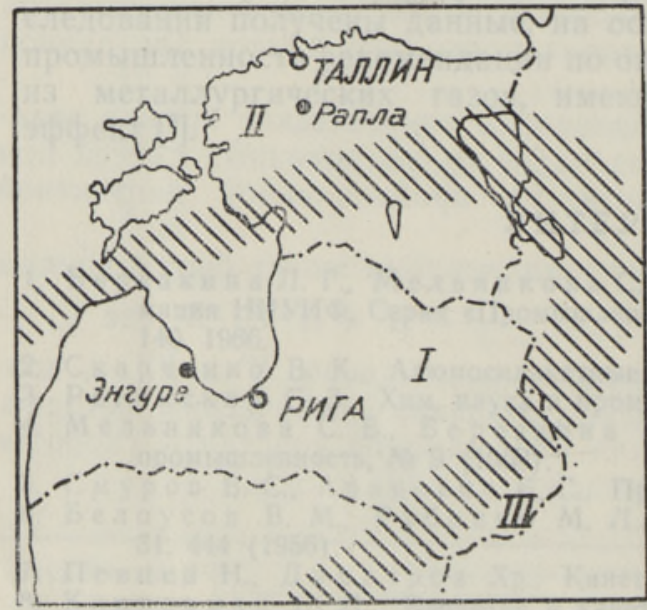

Рис. 1. Фациальная схема ордовика Северной и Средней Прибалтики.

Фациальные зоны: I - осевая, II - ceверная, III - южная. Штриховкой показана переходная полоса между фациальными зонами.

Скв. Рапла расположена недалеко от выходов ордовикских пород, примерно в средней части Северной Эстонии (рис. 1). Выбор скважины обусловлен, кроме удачного географического расположения еe в пределах северной фациальной зоны, также практически полным отсутствием эпигенетической доломитизации ее пород.

Керн скв. Рапла хранится в кернохранилище Института геологии АН ЭССР.

Методика литологического изучения, классификация пород по вещественному составу и по структурно-текстурным признакам, а также принципы представления фактического материала (рис. 2) не отличаются от ранее принятых (Пылма, 1972). Исключение составляет только выделение детрита моллюсков и группы неопределимых остатков (indeterminata). Необходимость выделения последней вызвана значительной 
перекристаллизацией детрита в северной фациальной зоне, особенно в горизонтах $\mathrm{B}_{\mathrm{II}}-\mathrm{C}_{\mathrm{I}} \mathrm{b}$.

Стратиграфическое расчленение средне- и верхнеордовикской части разреза проведено в основном по данным А. Рымусокса (Рыымусокс, $1966 ; 1970)$. При этом небольшие расхождения в мощностях горизонтов вызваны, вероятно, различиями в интерпретации глубин. Некоторые границы $\left(\mathrm{B}_{\mathrm{III}} / \mathrm{C}_{\mathrm{I}} \mathrm{a} ; \mathrm{C}_{\mathrm{I}} \mathrm{b} / \mathrm{C}_{\mathrm{I}} \mathrm{c} ; \mathrm{C}_{\mathrm{II}} / \mathrm{C}_{\mathrm{II}} ; \mathrm{E} / \mathrm{F}_{\mathrm{I}} \mathrm{a}\right)$ уточнены согласно результатам изучения микропланктона Р. Мяннилем. Расчленение нижнего ордовика проведено по литостратиграфическим схемам К. Орвику (1960) и С. Мяги (1970).

Из ордовикского карбонатного разреза скв. Рапла был отобран 201 образец со средним интервалом опробования 0,8 м. Было изготовлено 197 шлифов и произведено 145 химических анализов.

Химические анализы были выполнены Л. Сяга в химической лаборатории Института геологии АН ЭССР, а шлифы и пришлифовки изготовлены в шлифовальной лаборатории института Я. Нылваком. Рисунки оформлены Л. Липпертом. Названным выше лицам автор искренне признателен за помощь в работе.

\section{Общая литологическая характеристика разреза}

Карбонатные отложения ордовика в скв. Рапла пройдены в интервале $31,10-192,00$ м $\left(\mathrm{B}_{\mathrm{I}}-\mathrm{F}_{\mathrm{II}}\right)$. Они залегают на размытой поверхности черных граптолитовых аргиллитов пакерортского горизонта $\left(\mathrm{A}_{\Pi}\right)$ ордовика и перекрываются известняками и мергелями юуруского горизонта $\left(\mathrm{G}_{\mathrm{I}-\mathrm{II}}\right)$ силура. Базальным для известняков ордовика служит имеющий небольшую мощность $\left(0,7\right.$ м) латорпский горизонт $\left(\mathrm{B}_{\mathrm{I}}\right)$, представленный глауконитово-доломитовыми алевролитами и алевритисто-глауконитовыми доломитами с очень редкими обломками главным образом беззамковых брахиопод. Ордовик венчается также более терригенной маломощной $(0,6 \mu)$ камарикуской пачкой поркуниского горизонта $\left(\mathrm{F}_{\mathrm{II}} \mathrm{K}\right)$, керн которой не сохранился. По имеющимся данным, пачка представлена доломитовыми породами, содержащими в разной степени песчаный и алевритовый материал и характеризуемыми минимальным содержанием детрита.

В основной своей части данный ордовикский разрез представлен главным образом известняками разной степени глинистости. Содержание те р и генного компонента колеблется в пределах от 1,90 до $96,8 \%$. К чистым известнякам относится $38 \%$ всех изученных образцов; чистые и глинистые известняки вместе взятые (с содержанием терригенного компонента не более $25 \%$ ) составляют около $80 \%$ анализированных проб. При этом можно отметить значительные различия между средним содержанием терригенного компонента в интервалах $\mathrm{B}_{\mathrm{I}}-\mathrm{D}_{\text {III }}(18,2 \%)$ и $\mathrm{E}-\mathrm{F}_{\text {II }}(13,3 \%)$.

Повышенное содержание долом и т п прослеживается в низах ( $\mathrm{B}_{\mathrm{I}}$ и низы $\mathrm{B}_{\mathrm{II}}$ ) и верхах ордовика (начиная с верхней половины $\mathrm{F}_{\mathrm{I}} \mathrm{c}$ ). Среднее содержание доломита в породах недоломитизированной части разреза $5,1 \%$, а общее среднее содержание по всему карбонатному разрезу ордовика $11,2 \%(2,0-88,1 \%)$. Форма кристаллов в подавляющем числе ромбоэдрическая размером от 0,02 до 0,12 мм, в среднем же около 0,04 мм. В сильно доломитизированных интервалах часто просле. живается мелкокристал.ичческая мозаичная структура.

В то р и н ы й кальци т (заполняющий поры) в изученном разрезе присутствует практически во всех образцах. Преобладающий диаметр кристаллов $0,03-0,07$ мм. Его не удалось установить только в сильно 
доломитизированных интервалах. Среднее содержание этого компонента в породах $4,1 \%(0,1-29,2 \%)$. Повышенное количество вторичного кальцита встречено в горизонтах $\mathrm{C}_{\mathrm{I}} \mathrm{b}$ и $\mathrm{F}_{\mathrm{II}}$.

С труктура основной м а с сы главным образом микрокристаллическая; скрытокристаллическая (афанитовая) разновидность появляется начиная с кейлаского горизонта $\left(\mathrm{D}_{\mathrm{II}}\right)$. В доломитизированных интервалах преобладает тонко- и мелкокристаллическая основная масса.

В скв. Рапла, как это и характерно для всей северной фациальной зоны, в горизонтах $\mathrm{B}_{\mathrm{III}}, \mathrm{C}_{\mathrm{I}}$ a и $\mathrm{C}_{\mathrm{I}} \mathrm{b}$ встречены прослойки известняка с гетитовыми (корнчневые) и франколитовыми (белые) о олит а м и. Максимальный диаметр оолитов колеблется в пределах от 0,2 до 1,6 мм. Среднее содержание их в породах $8,3 \% \quad(0,5-48,0 \%)$. В пределах $\mathrm{B}_{\text {II }}$ оно $22,2 \%$, а в $\mathrm{C}_{\mathrm{I}}$ - $3,0 \%$. О минералогическом составе белых оолитов существуют различные мнения. Эти оолиты рассматривались или как преимущественно кальцитовые (Orviku, 1940), или шамозитовые (Hessland, 1949; Пылма, 1967; Вингисаар, 1971), или карбонатные и фосфатные (Мяги, 1970). По последним рентгенографическим определениям К. Утсала (кабинет минералогии Тартуского государственного университета), в белых оолитах из скв. Рапла, а также других мест северной фациальной зоны преобладает франколит (фосфат кальция) с примесью гетита.

Гл ау кони т в основном связан с горизонтами $\mathrm{B}_{\mathrm{I}}-\mathrm{B}_{\mathrm{III}}$. Размер зерен колеблется от 0,01 до 1,3 мм (в среднем $0,1-0,2$ мм). Среднее содержание зерен глауконита в породах $\mathrm{B}_{\mathrm{I}}-\mathrm{B}_{\mathrm{II}} 7,8 \%$ с максимумом $37,3 \%$ B B . В остальной части изученного разреза глауконит встречен спорадически, в качестве редких мелких зерен $\left(\mathrm{C}_{\mathrm{I}} \mathrm{c}, \mathrm{C}_{\mathrm{II}}\right)$, или покрывает тонкой пленкой поверхности перерыва ( $\left.\mathrm{F}_{\mathrm{I}} \mathrm{a}, \mathrm{F}_{\mathrm{I}} \mathrm{b}\right)$.

K е р оген в скв. Рапла установлен в интервале от $\mathrm{B}_{\mathrm{II}}$ до $\mathrm{F}_{\mathrm{I}} \mathrm{a}$, полностью отсутствует он в $\mathrm{C}_{\mathrm{I}} \mathrm{b}$. Среднее содержание керогена в породах по данным 21 шлифа $2,8 \%(0,2-13,5 \%)$.

С густковы й м а тери л часто встречается лишь на двух уровнях: в подгоризонте $D_{\text {II }} \beta$ (не более $2 \%$ ) и в горизонте $F_{\text {II }}$ (не более $6 \%$ ). Единичные небольшие скопления сгустков отмечены в горизонтах $\mathrm{C}_{\mathrm{I}} \mathrm{b}$, $\mathrm{E}$ и $\mathrm{F}_{\mathrm{I}} \mathrm{c}$ в так наз. «ловушках» (под опрокинутыми створками брахиопод, в створках гастропод и т. д.), защищенных от кон- и постседиментационных изменений. Размеры сгустков в среднем составляют $0,04-0,05$ мм; форма их округлая или овальная.

Обломочный карбонатны й м тери ал представлен главным образом псефитовым компонентом (размер частиц более 1,0 мм). Псаммит $(0,1-1,0$ мм) встречен в незначительном количестве только в верхах $F_{\mathrm{I}} \mathrm{c}$ и в $\mathrm{F}_{\mathrm{II}}$. С равнительно постоянным присутствием псефитового материала характеризуется нижний ордовик (особенно $\mathrm{B}_{\mathrm{III}}$ ) и верхи верхнего ордовика $\left(\mathrm{F}_{\mathrm{I}} \mathrm{c}-\mathrm{F}_{\mathrm{II}}\right)$. В горизонтах $\mathrm{C}_{\mathrm{III}}-\mathrm{D}_{\mathrm{II}}$ псефит в изученном разрезе отсутствует. Преобладающий размер обломочных частиц 510 мм, а максимальный не превышает 40 мм. Форма зерен неправильная. Окатанность в основном слабая, хорошая окатанность отмечена только в верхнем ордовике. В нижнем и среднем ордовике на псефитовых частицах преобладает фосфатная, а в верхнем ордовике пиритовая импрегнация.

В разрезе скв. Рапла (особенно в $\mathrm{O}_{3}$ ) широко распространены ясно выраженные комковаты е текстуры, указывающие на значительную дифференциацию терригенного и карбонатного компонентов уже в процессе осадконакопления (Ораспыльд, 1964). В остальной части изученного разреза развита в основном тонко- и среднеслоистая слабо вол- 


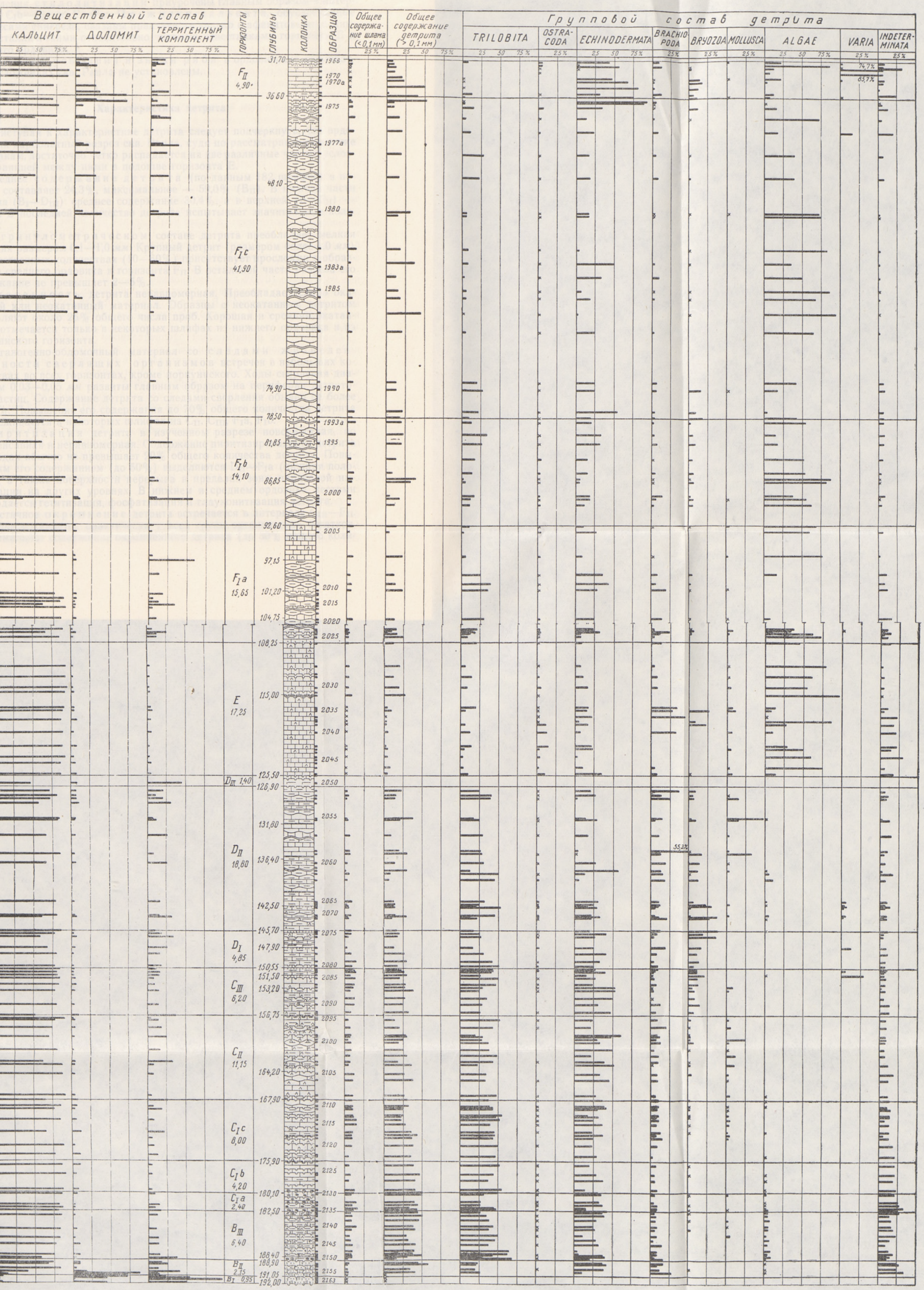

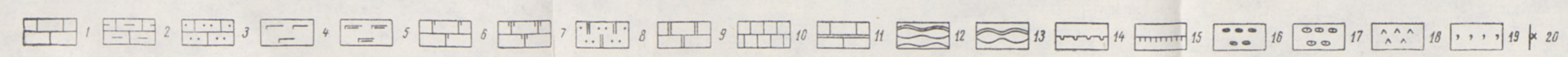


нистая текстура. Микрослойчатость установлена только в двух образцах из Е и $\mathrm{F}_{\mathrm{I}}$.

Общее количество зафиксированных пов ерхностей переры в а около 100. Подавляющая часть их сосредоточена в интервалах $\mathrm{B}_{\mathrm{I}}-\mathrm{C}_{\mathrm{III}}$ и $\mathrm{F}_{\mathrm{I}} \mathrm{C}-\mathrm{F}_{\mathrm{II}}$. B нижнем ордовике преобладают гетитовая и франколитовая (фосфатная), в среднем ордовике франколитовая и пиритовая, а в верхнем ордовике пиритовая импрегнация. В интервалах с относительно частыми поверхностями перерыва повышено содержание шлама и детрита.

Явления с ти лоли т и 3 а ци и приурочены главным образом к интервалам $\mathrm{C}_{\mathrm{I}} \mathrm{b}-\mathrm{C}_{\mathrm{I}} \mathrm{c}$ и $\mathrm{E}-\mathrm{F}_{\Pi}$. П рож ил к и к аль и т а, обусловленные процессами синереза, связаны практически только с афанитовыми и микрокристаллическими относительно чистыми известняками горизонта $\mathrm{E}$ и верхнего ордовика.

Трещины усыхания и знаки ряб и в ордовикских карбонатных отложениях скв. Рапла не установлены,

\section{Характеристика детрита}

Приступая к характеристике детрита следует подчеркнуть, что ордовикский карбонатный разрез скв. Рапла, судя по рассматриваемым ниже признакам, достаточно четко распадается на две различные части с условной границей между ними в подошве горизонта Е.

Среднее содержан ие де т р и а (по данным 182 шлифов) в породах составляет $24,3 \%$, максимальное - 59,0\% (BII). В нижней части разреза $\left(\mathrm{B}_{\mathrm{I}}-\mathrm{D}_{\mathrm{III}}\right)$ среднее содержание $30,4 \%$, а в верхней $\left(\mathrm{E}-\mathrm{F}_{\mathrm{II}}\right)$ $16,0 \%$. В последней количество детрита испытывает значительные колебания.

В гранулометрическом составе детрита преобладает мелкая фракция размером 0,1-1,0 мм. Крупный детрит (размером более 1,0 мм) в существенных количествах $(10-60 \%)$ присутствует прослоями в образцах из среднего ордовика и горизонта $F_{\text {II. }}$ В остальной части разреза его содержание не превышает $2-5 \%$.

О к а т а н о с т ь детрита неравномерная. Преобладает слабо окатанный или неокатанный материал. Образцы с неокатанным детритом составляют около $25 \%$ общего числа проб. Хорошая и средняя окатанность отмечается только в некоторых шлифах из нижнего ордовика и из поркуниского горизонта.

Органогенно-обломочный материал со следа ми жизнедея тельности сверлящих организ мов встречен в небольших количествах во всех горизонтах, кроме поркуниского. Ходы сверления диаметром 0,03-0,05 мм развиты главным образом на периферии детритовых частиц. Содержание детрита со следами сверления обычно не более $5-10 \%$. Повышение его содержания до $70 \%$ общего количества детрита прослеживается в некоторых шлифах из $\mathrm{C}_{\mathrm{II}}, \mathrm{C}_{\mathrm{III}}, \mathrm{F}_{\mathrm{I}} \mathrm{a}, \mathrm{F}_{\mathrm{I}} \mathrm{b}$.

Пи ри ти за ц я детрита в изученном разрезе повсеместная, но неинтенсивная и неравномерная. Содержание пиритизированного детрита в породах обычно не превышает $20 \%$ общего количества детрита. Повышенным его содержанием (до $50 \%$ ) выделяются $\mathrm{D}_{\mathrm{II}}-\mathrm{F}_{\mathrm{I}}$ (нижняя половина), а также поверхности перерыва в пределах зоны пиритовой импрегнации на других уровнях. В нижнем и среднем ордовике местами наблюдается гетитизация, фосфатизация и глауконитизация детрита.

Частичное о крем нен и е детрита встречается в интервале $\mathrm{C}_{I I}-\mathrm{F}_{\mathrm{II}}$. Оно прослеживается практически у всех групп органических остатков. Максимальное содержание окремненного детрита (до $30 \%$ общего коли- 
чества детрита) приурочено к горизонтам $\mathrm{D}_{\mathrm{I}}$ и $\mathrm{D}_{\mathrm{II}}$. В остальной части этого интервала встречаются только редкие проявления окремнения.

Пространственное распределение детрита в породах большей частью неравномерное. При этом часто отмечается тенденция к концентрации детрита в небольшие (диаметром $1-5 \mathrm{~cm}$ ) неправильной формы скопления, оссбенно в интервале $\mathrm{C}_{\Pi}-\mathrm{D}_{I I I}$. Равномерное распределение его более характерно для верхнего ордовика. Послойная или линзовидная концентрация детрита встречена как исключение только в некоторых образцах из $\mathrm{C}_{1}, \mathrm{E}$ и $\mathrm{F}_{\mathrm{I}}$.

В большинстве случаев детрит в породах неориентиров а н ны й. Только в $15 \%$ всех изученных проб прослеживается слабо выраженная горизонтальная упаковка органогенно-обломочного материала (в основном крупного), особенно в верхнем ордовике. В нижнем ордовике, а также в $\mathrm{F}_{\mathrm{I}} \mathrm{a}-\mathrm{F}_{\mathrm{I}} \mathrm{b}$ нередко встречается концентрическое расположение детрита вокруг и внутри ходов илоедов.

Среднее содерж ание шл а м $6,5 \%$. При этом оно несколько различно в интервалах $\mathrm{B}_{\mathrm{I}}-\mathrm{D}_{\mathrm{III}}(7,9 \%)$ и $\mathrm{E}-\mathrm{F}_{\mathrm{II}}(4,5 \%)$. Относительно высоким содержанием выделяются интервал $\mathrm{B}_{\mathrm{II}}-\mathrm{C}_{\mathrm{II}}$ и верхняя половина $\mathrm{F}_{\mathrm{I}} \mathrm{b}$.

Детрит водорослей, трилобитов и иглокожих составляет преобладающую массу органогенно-обломочного материала в данном разрезе.

В водорослевом детрите чаще всего встречаются остатки скелетов Dasyporella, Vermiporella, Cyclocrinites, Coelosphaeridium и Mastopora. Эта группа детрита является основной породообразующей группой организмов в интервале $E-F_{I} c$, где среднее содержание его $45 \%$, при чем максимальное содержание достигает $97,6 \%$ (E). В остальной части ордовикского карбонатного разреза данной скважины среднее содержание водорослевого детрита более чем в десять раз ниже (3,7\%). Максимальным здесь является содержание $11,4 \%$ (D более постоянным содержанием водорослевого детрита выделяются горизонты $\mathrm{B}_{\text {III }}$, С га и нижняя половина $\mathrm{D}_{\text {II. }}$.

Среднее содержание т р и лоби то в ого детрита $27,0 \%$. Максимальное количество $(69,0 \%)$ зафиксировано в $\mathrm{B}_{\text {III. }}$ В интервале $\mathrm{B}_{\mathrm{I}}-\mathrm{D}_{\text {II }}$ трилобиты вместе с иглокожими становятся основными детритообразующими группами организмов. В этом интервале среднее содержание обломков трилобитов $36,0 \%$, а в промежутке $E-F_{I I} 13,2 \%$ с максимумом в $F_{I} a$ $(39,0 \%)$.

Сравнительно равномерным распределением выделяются иглокожевый, брахиоподовый и, в меньшей степени, остракодовый детрит.

Остатки иглокожих представлены в основном разными частями криноидей (членики стеблей и рук, обломки корней) и редкими остатками цистоидей, бластсидей и морских ежей. Среднее содержание этой группы детрита составляет $27,9 \%$, а максимальное - 93,5\% ( $\left.\mathrm{F}_{\mathrm{II}}\right)$. Более высоким содержанием иглокожевого детрита характеризуются $\mathrm{C}_{\mathrm{II}}, \mathrm{C}_{\mathrm{III}}$ и особенно $\mathrm{F}_{\mathrm{II}}$.

Во всех горизонтах присутствуют обломки замковых, реже беззамковых бр ах и о под. Среднее содержание брахиоподового детрита $9,1 \%$, а максимальное - $55,3 \%\left(\mathrm{D}_{\mathrm{II}}\right)$. Чаще всего он отмечается в горизонтах BII, D II и Е. По имеющимся данным (Ланг, 1970; Вингисаар, 1971), это самая устойчивая группа детрита (по среднему содержанию) в пределах северной структурно-фациальной зоны.

О с т р ко до вы й детрит в изученном разрезе присутствует в небольших количествах. Максимальное его содержание не превышает $14,3 \%$ (Е). Среднее содержание по всему разрезу $2,1 \%$; в интервале $\mathrm{B}_{\mathrm{I}}-\mathrm{D}_{\mathrm{III}}$ оно $1,3 \%$, а в $\mathrm{E}-\mathrm{F}_{\mathrm{II}}$ составляет $2,9 \%$. В более существенном 
количестве остракодовый детрит установлен в скрыт)- и микрокристаллических известняках $\mathrm{E}$ и $\mathrm{F}_{\mathrm{I}} \mathrm{a}$.

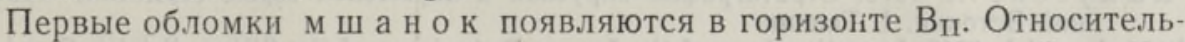
но высоким содержанием мшанкового детрита выделяются $\mathrm{C}_{\mathrm{II}}-\mathrm{D}_{\mathrm{II}}$, средняя часть $\mathrm{E}, \mathrm{F}_{\mathrm{I}} \mathrm{b}$ и $\mathrm{F}_{\mathrm{II}}$. Максимальное количество $(38,5 \%)$ его встречено в нижней половине $\mathrm{D}_{\text {II }}$. Среднее содержание в шлифах по разрезу скв. Рапла составляет 9,3\%. В скв. Хаапсалу детрит мшанок местами (особенно в $\mathrm{C}_{\mathrm{III}}-\mathrm{D}_{\mathrm{I}}$ ) служит основной породообразующей группой орга низмов (Вингисаар, 1971).

Детрит м ол юско в представлен в изученном разрезе главным образом фрагментами головоногих (преобладают в нижнем ордовике), брюхоногих и двустворчатых (преобладают в среднем и верхнем ордовике). Первые определимые остатки моллюсков появляются в $\mathrm{B}_{\text {III. Они }}$ встречаются в шлифах спорадически со средним содержанием 5,5\% . Почти полным отсутствием детрита моллюсков выделяются $\mathrm{C}_{\mathrm{I}} \mathrm{b}, \mathrm{D}_{\mathrm{I}}, \mathrm{F}_{\mathrm{I}} \mathrm{b}$ и $\mathrm{F}_{\mathrm{I}}$. Повышенное содержание его отмечено в средней части $\mathrm{C}_{\mathrm{II}}$ и в верхней половине $\mathrm{D}_{\text {II }}$ (до $48 \%$ ).

B группу v a ria, в интервале $\mathrm{C}_{\mathrm{II}}-\mathrm{D}_{\text {II }}$ вошли главным образом разрозненные окремнелые спикулы губок, а в верхнем ордовике (особенно в $\left.F_{\text {II }}\right)$ - детрит ругоз, табулят и строматопор. Необходимость выделения этой группы возникла при изучении 17 шлифов, где количество детрита по указанным группам фауны доходит до $85,7 \%$ ( $\left.\mathrm{F}_{\mathrm{II}}\right)$, а среднее содержание составляет $15,3 \%$.

Группа неопредели мых органических ост атков (indeterminat a) встречается в количестве не более $34,0 \%$ ( $\left.\mathrm{B}_{\Pi}\right)$, а среднее их содержание в скважине $11,5 \%$. Отмечается тенденция уменьшения содержания неопределимых остатков в сторону верхнего ордовика. Так, в интервале $\mathrm{B}_{\mathrm{I}}-\mathrm{C}_{\mathrm{I}} \mathrm{c}$ они составляют в среднем $18,5 \%$, а в интервале $\mathrm{E} \rightarrow \mathrm{F}_{\mathrm{II}}-9,0 \%$.

Подытоживая изложенное выше, ограничимся здесь лишь некоторыми самыми общими замечаниями. Сравнение полученных данных с таковыми для осевой фациальной зоны (Пылма, 1972) показывает, что осадконакопление в северной фациальной зоне в изученном отрезке ордовикского периода протекало в более подвижной водной среде и с более частыми перерывами, чем это имело место в осевой фациальной зоне. По ряду структурных и текстурных признаков изученный разрез можно разделить на две части, охватывающие горизонты соответственно в интервалах $\mathrm{B}_{\mathrm{I}}-\mathrm{D}_{\mathrm{II}}$ и $\mathrm{E}-\mathrm{F}_{\mathrm{II}}$. На наш взгляд, такое деление разреза обусловлено прежде всего различиями в характере тектонического развития данной территории.

\section{Л И Т Е Р А Т Р А}

Вингиса ар П. 1971. Микролитологическое исследование известняков ордовикского разреза скважины Хаапсалу. Изв. АН ЭССР, Хим. Геол., 20, № 1.

Л анг Т. 1970. Фащин детрита среднеордовикской сланщеносной толщи Севера Прибалтики. Тезисы докл. VII науч. конфер. геологов Прибалтики и Белоруссии. Таллин.

Мяги С. 1970. Отложения онтикаского яруса Средней и Западной Эстонии. Изв. АН ЭССР, Хим. Геол., 19, № 2.

Ор асп пы ьд А. 1964. О некоторых текстурах карбонатных пород харьюской серин (верхнего ордовика) в Эстонии. Уч. зап. Тартуск. гос. ун-та, вып. 153.

О р в и ку К. К. 1960. О литостратиграфии волховского и кундаского горизонтов в Эстонии. Тр. Ин-та геол. АН ЭССР, $\mathbf{V}$.

Пылм а Л. 1967. О переходной полосе между северной и осевой фациальными зонами ордовика Прибалтики. Изв. АН ЭССР, Хим. Геол., 16, № 3.

Пыл м а Л. 1972. Состав и количество детрита в отложениях осевой фациальной зоны ордовика Прибалтики (по скважине Энгуре). Изв. АН ЭССР, Хим. Геол., 21, № 2. 
Ры ы усокс А. 1966. Стратиграфия вируской и харьюской серий (ордовик) Северной Эстонии. Дисс. докт, геол.-мин. н. Тарту.

Р ы м у сокс А. 1970. Стратиграфия вируской и харьюской серий (ордовик) Северной Эстонии. І. Таллин.

Hess 1 and I. 1949. Investigations of the Lower Ordovician of the Siljan district, Sweden. IV. Lithogenesis and changes of level in the Siljan district during a period of the Lower Ordovician. Bull. Geol. Inst. Uppsala, XXXIII.

O r viku K. 1940. Lithologie der Tallinna-Serie (Ordovizium, Estland). I. Acta et Comm. Univ. Tartuensis, XXXIV.

Ннститут геологии

Академии наук Эстонской ССР

Поступила в редакцию 12/VI 1972

L. POLMA

\title{
DETRIIDI KOOSTIS JA HULK BALTIKUMI ORDOVIITSIUMIBASSEINI PÖHJAVOONDI SETETES
}

\author{
(Rapla puursüdamiku alusel)
}

Artiklis esitatakse üks osa Baltikumi ordoviitsiumibasseini pōhja- ja keskvööndi setete võrdleva uurimise tulemustest, iseloomustades Rapla puursüdamiku alusel põhjavööndi karbonaatkivimites sisalduva detriidi suhtelist hulka, morfoloogiat ja leviku seaduspärasusi ning detriiti moodustavate fossiilirühmade esinemissagedust. Lühidalt peatutakse ka uuritud kivımite teistel struktuursetel ja tekstuursetel põhitunnustel. Uurimistöö tulemused näitavad, et antud piirkonnale olid kõnesoleval ajavahemikul iseloomulikud liikuvamaveelised settimistingimused kui need esinesid vastavate keskvoöndi setete puhul (Пылма, 1972), Paljude uuritud tunnuste alusel jaguneb käsiteldav läbilōige kaheks litoloogiliselt erinevaks intervalliks: $B_{I}-D_{I I I}$ ja $E-F_{I I}$. Tōenäoliselt on erinevused nende intervallide vahel tingitud peamiselt tektoonilise arengu omapärast.

\section{POLMA}

\section{SKELETAL DEBRIS CONTENT AND COMPOSITION IN THE SEDIMENTS OF THE NORTHERN FACIAL BELT OF THE EAST BALTIC ORDOVICIAN}

\section{(Rapla boring)}

The present paper is a continuation of our studies on the carbonate rocks of the northern and axial facial belts of the East Baltic Ordovician. The content of skeletal debris and the frequency of occurrence of debris-forming faunal groups in the Lower ArenigianUpper Ashgillian sequence of the Rapla core, northern facial belt (Fig. 1), has been studied by the point-counting method (Fig. 2). Other structural and textural features are considered in brief. The average debris content in the samples analyzed is 24.3 per cent. There are essential differences in the average debris conient between the core intervals corresponding to the stages $\mathrm{B}_{\mathrm{I}}-\mathrm{D}_{\mathrm{III}}(30.4 \%)$ and $\mathrm{E}-\mathrm{F}_{\mathrm{II}}(16.0 \%)$. Trilobites and echinoderms are prevailing among the debris-forming faunal groups in the interval of $\mathrm{B}_{\mathrm{I}}-\mathrm{D}_{\mathrm{III}}$ and algae

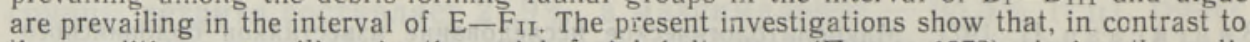
the conditions prevailing in the axial facial belt area (Пылма, 1972), during the sedimentation of the Ordovician carbonate sequence more agitated environments were prevailing in the northern facial belt of the Eas! Baltic area. On the basis of the studied characters the Ordovician carbonate sequence of the Rapla core may be divided into two lithologically different intervals: $B_{I}-D_{I I I}$ and $E-F_{11}$, probably induced by different tectonic patterns. 